\title{
Management of frontobasal nasal fractures: a multidisciplinary approach.
}

\author{
Brihaspati Sigdel $^{1}$, Shabal Sapkota ${ }^{2}$ \\ ${ }^{1}$ Associate Professor \& HOD, Department of Otolaryngology \& Head and Neck Surgery, Gandaki Medical College, Pokhara, \\ Nepal, ${ }^{2}$ Assistant Professor, Department of Neurosurgery, Gandaki Medical College, Pokhara, Nepal.
}

Received: June 15, 2020

Accepted: August 01, 2020

Published: September 01, 2020

Cite this paper:

Sigdel B, Sapkota S. Management of frontobasal nasal fractures: a multidisciplinary approach. Journal of Brain and Spine Foundation Nepal. 2020;1(1):11-15

Correspondence:

Dr. Brihaspati Sigdel

Associate Professor and Head

Department of Otolaryngology \& Head and Neck Surgery,

Gandaki Medical College Teaching Hospital, Pokhara, Nepal.

Email: brihassig1@gmail.com

https://orcid.org/0000-0002-8546-6699

\begin{abstract}
Introduction: Frontonasal fracture and concomitant craniofacial injuries carry the significant potential for mortality and morbidity mainly in young adults. This study analyses the characteristics of frontonasal injuries and associated facial injuries, the management option, and its outcome. Methods: This retrospective study was performed at the Department of Otolaryngology and Head and Neck Surgery and Neurosurgery, Gandaki Medical College, Pokhara, Nepal. Patients who had undergone surgery for cranial and midline facial bone fracture between January 2018 to June 2020 were included in this study. The variable examined were age, sex, alcohol consumption, any chronic diseases, time from accident to surgery, duration of hospitalization, and postoperative complication. Continuous variables were expressed as mean \pm standard deviation, and categorical variables were expressed as number or percentage. All analyses were performed using SPSS software 26.0. Results: The majority of patients were in the 3rd to 4th decade (67.1\%). The most common cause was Road traffic accidents 45(59.2\%). Twenty Five (32.9\%) patients had consumed alcohol at the time of the accident. Among midline anterior fracture most common finding was nasal bone fracture 42(55.3\%). Frontal bone fracture was seen in $9(11.8 \%)$ cases. Closed reduction of nasal bone was performed in $43(56.58 \%$ ) cases. Craniotomy and elevation of depressed frontal bone was done in $10.53 \%$ of cases. Conclusion: Road traffic accidents were found to be the commonest mode of frontonasal trauma and males in young adult age group were the most common victim. The most common injuries were nasal bone fracture which was managed by closed reduction.
\end{abstract}

Key words: Fractures, Maxillofacial injuries, Nasal bone, Skull fracture.

\section{Introduction}

The frontobasal nasal region plays an important role in function and esthetics. Fracture in this region causes functional and esthetic complications. ${ }^{1}$ In extreme cases, it leads to permanent damage. It harms social activities and may result in economic and psychological problems. $^{2}$

It is of utmost importance to achieve desirable recovery from frontonasal injury. For that, first aid, emergency treatment and successive treatment should be appropriate planned and delivered. Treatment should be done according to appropriate guidelines based on the causes of injury and the patient's findings. The treatment plan depends on age, geographic location and ethnic groups. ${ }^{3,4}$ Therefore it should be continuously updating fracture patterns.

This study was conducted to analyses frontonasal nasal fracture in the past two years. The purpose of this study 
was to update the information on fracture patterns and its treatment in tertiary center hospital, Pokhara, Nepal.

\section{Methods:}

This is a retrospective study done in the Department of Otolaryngology and Head and Neck Surgery and Neurosurgery, Gandaki Medical College Teaching hospital, Pokhara, Nepal. Patients who had undergone surgery for cranial and midline facial bone fracture between July 2018 to June 2020 have been included in this study. Patients treated with conservative management were excluded. The variable examined were age, sex, alcohol consumption at the time of the accident, type of fracture, treatment provided, duration of hospitalization, and postoperative complication. The causes of the fracture were categorized into fall injuries, road traffic accidents, sports injuries, physical assaults, accidents involving automobile injuries, etc. Surgery was performed by faculties with experiences in otolaryngology for at least five years. The cranial part of injury was treated by the neurosurgeon and maxillofacial injury was treated by the maxillofacial surgeon. Evaluation of all cases and emergency management was done as required. Computed Tomography (CT) scan of the paranasal sinus and head was done in all cases. Pre-anesthesia checkup was done by the anesthesia team and the type of intubation discussed according to the condition of the patient. All patients were operated under General Anesthesia. Most of the cases were performed in a single setting. The cranial injury and open nasal bone fracture were done on an emergency basis. Isolated closed nasal bone fracture were treated either within $72 \mathrm{hrs}$ of injury or after 7-10 days of injury to subside swelling. After surgery, Merocele nasal tampon and external nasal splinting were maintained for four and seven days respectively. The patients were followed up for at least three months to assess the complication. Continuous variables were expressed as mean \pm standard deviation, and categorical variables were expressed as number or percentage. All analyses were performed using the IBM SPSS software (version 26.0).

\section{Results:}

The total number of patients in our study was seventysix. The age of patient ranged from 7-70 years with mean age of $30.2 \pm 12.7$ years. Male patients were 53 (69.7\%) and female 23 (30.3\% with male to female ratio 2.3:1. The majority of patients were in the 3rd to 4th decade (67.1\%) (Table 1).

Table 1. Age group of patients

\begin{tabular}{lll}
\hline Age group & No. & Percentage (\%) \\
\hline$<10$ & 2 & 2.6 \\
$11-20$ & 11 & 14.6 \\
$21-30$ & 32 & 42.1 \\
$31-40$ & 19 & 25.0 \\
$41-50$ & 7 & 9.2 \\
$>50$ & 5 & 6.5 \\
Total & 76 & 100
\end{tabular}

The most common cause of injury was road traffic accidents 45 (59.2\%) followed by fall injuries 21 (27.6\%). Twenty five (32.9\%) patients had consumed alcohol at the time of the accident. The nasal bone fracture was found to be the commonest midline anterior fracture seen in $42(55.3 \%)$ cases. Frontal bone fracture occurred in 9 (11.8\%) cases (Table 2). Closed reduction of nasal bone was performed in 43 (56.58\%) cases. Craniotomy and elevation of depressed frontal bone were performed in $10.53 \%$ of cases (Table 3). Two patients have developed wound infection. Out of two, one was treated conservatively, the other one develops extradural abscess draining into the sinus at the root of the nose, needing re-exploration. 
Table 2. Diagnosis of frontobasal nasal fracture

\begin{tabular}{lll}
\hline Diagnosis & No. & Percentage \\
\hline Isolated Nasal bone fracture & 42 & $55.3 \%$ \\
Isolated Frontal bone fracture & 9 & $11.8 \%$ \\
Nasal bone fracture and DNS & 7 & $9.2 \%$ \\
Naso-septal fracture with DNS & 6 & $7.9 \%$ \\
Frontonasal fracture & 5 & $6.6 \%$ \\
Frontonasal fracture with & 4 & $5.3 \%$ \\
EDH & & \\
Frontonasal and maxillary & 3 & $3.9 \%$ \\
fracture & & \\
Total & 76 & 100 \\
\hline
\end{tabular}

*EDH:Extradural hematoma, **DNS: Deviated nasal septum

\section{Discussion:}

Most of the cases presenting in our study were ranging between 21-30 years followed by 31-40 years. Male to female ratio in our study was 2.3:1. Byun et al. in their series, found that male patients were 3.3 times greater than the number of female patients and twenties were the most common age group. ${ }^{5}$ Similar finding also was noted in a study by Kim et al. ${ }^{6}$ This shows that males are more vulnerable to have frontobasal nasal fractures. This may be due to the reason that males have more freedom to public exposure such as partying late night, driving as compared to females in our society and they are supposed to work outside home which makes them more exposed to accidents and fall injuries. Road traffic accidents were the commonest causes of frontobasal nasal fractures accounting for $59.2 \%$ of cases which is slightly higher than the study done by Motamedi et al. ( $54 \%){ }^{7}$ This may be due to the poor quality of roads in our part of the world with excessive breakers and potholes, negligence of the driver, poor maintenance of vehicles, driving under the influence of alcohol, and not following traffic rules. Alcohol associated accidents in which craniofacial injuries are more common are mainly seen in young adults who drink and drive. ${ }^{8}$
Table 3. Treatment frontobasal nasal fracture

\begin{tabular}{lll}
\hline Type of surgery performed & No. & Percentage \\
\hline Closed reduction of nasal bone & 43 & $56.6 \%$ \\
Elevation of depressed fracture & 8 & $10.5 \%$ \\
$\begin{array}{l}\text { Closed reduction of nasal bone } \\
\text { septorhinoplasty }\end{array}$ & 6 & $7.9 \%$ \\
$\begin{array}{l}\text { Frontal sinus cranialization and } \\
\text { nasal bone reduction }\end{array}$ & 5 & $6.6 \%$ \\
$\begin{array}{l}\text { Craniotomy and evacuation of } \\
\text { EDH }\end{array}$ & 4 & $5.3 \%$ \\
Cranioplasty (Acrylic) with nasal \\
reduction with maxilla fixation
\end{tabular}

Closed reduction of nasal bone $\quad 2 \quad 2.6 \%$ septoplasty

Open nasal bone reduction $\quad 2 \quad 2.6 \%$

Open nasal bone reduction $+\quad 1 \quad 1.3 \%$ septoplasty

Open nasal bone reduction $\quad 1 \quad 1.3 \%$
+septorhinoplasty

Total $76 \quad 100$

*EDH: Extradural hematoma

Fall injuries were the second most common cause accounting to $27.6 \%$ cases, whereas in a study by Ong TK et al. fall injuries were reported to be $32 \% .{ }^{9}$ Many people in villages of our country climb trees to get grass to feed their livestock which may be the reason for such accidents in our part of the world. Other than those reasons, violence between people is also common in many societies particularly in the lower class families which mainly occurs due to the consumption of alcohol and various drugs. ${ }^{10}$ We recommend a CT scan of Head, Nose, and paranasal sinuses to each case of fracture so that any injury present will not be missed. The isolated nasal bone fracture was 
found in $55.3 \%$ of cases in our study whereas in a study by Su Jin et al. it was seen in $48.6 \%$ of cases. ${ }^{11}$ Combined fracture of the nasal bone and frontal bone occurred in $6.6 \%$ of cases. We did craniotomy followed by frontal bone elevation or cranialization of frontal sinus, duroplasty, extradural hematoma evacuation and nasal bone reduction in single setting in such cases. All the cases recovered without any complication. Isolated nasal bone fractures was managed by fixing within 24 hours if the patient presented to the hospital within that period. Surgery for patients who came late with swelling in the face without any cranial injury were delayed until facial swelling subside. It may take a week for an accurate assessment of the nasal framework and fixation. Patients with open nasal bone fracture and frontonasal fracture were fixed immediately (Figure 1). In the case of open frontobasal nasal fracture, both frontal and nasal fracture is managed in a single sitting by neurosurgeon and otolaryngology surgeon. ${ }^{12,13}$ This will reduce unnecessary exposure to general anesthesia and reduce the morbidity of the patients.
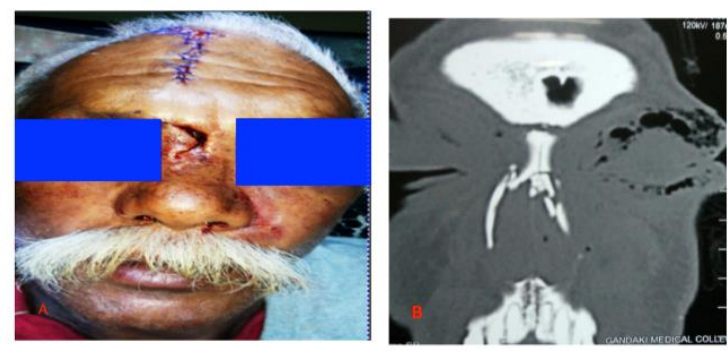

Figure 1 A. Frontobasal nasal fracture B. CT scan showing comminuted bilateral nasal bone fracture

Loss of consciousness is commonly seen in patients with an intracranial injury. However, it is less common in isolated nasal bone fractures. Patients who sustain moderate to severe head injury are usually associated with the complexity of frontobasal nasal fracture. Other injuries such as cervical spine injuries are very low. There should be a high index of suspicion of concomitant cervical spine fracture i.e., up to $10 \%$ associated with spine injuries whereas $8.86 \%$ case were seen in a study done by Elahi et al. ${ }^{14}$ All patients who had a depressed fracture of the frontal bone associated with extradural hematoma underwent craniotomy and evacuation of extradural hematoma. ${ }^{15}$ Patients with a mild head injury that were managed conservatively were excluded from this study. Our management protocol is to evaluate the craniofacial injury by both neurosurgeons and ENT surgeons and proceeds necessary treatment as far as possible in a single sitting. Cranialization of frontal sinus is done in a comminuted fracture of the posterior wall of the frontal sinus. (Figure 2.)

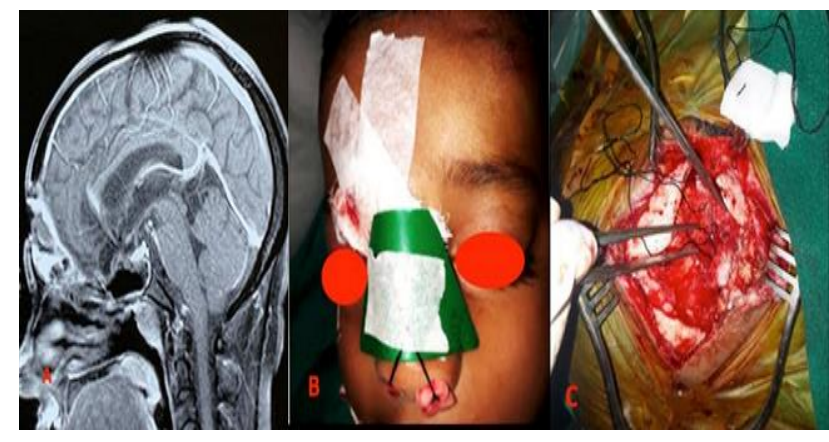

Figure 2 A. MRI showing severe frontobasal nasal fracture B. Closed reduction of nasal fracture and merocele packing C. Cranialization of frontal sinus and duroplasty

The complication in this study is found to be very low. The incidence of post-surgical complications ranges from 5-5.7\% including infection, asymmetry, and malocclusion. ${ }^{16}$ Two patients developed wound infection. Of them, one was treated conservatively and other developed an extradural abscess draining into the sinus at the root of the nose needing reexploration (Figure 3). There was no mortality in our study. The limitation of this study is the retrospective type of the study leading to gap in information and 
incomplete records, the accuracy of the original examination, and documentation.

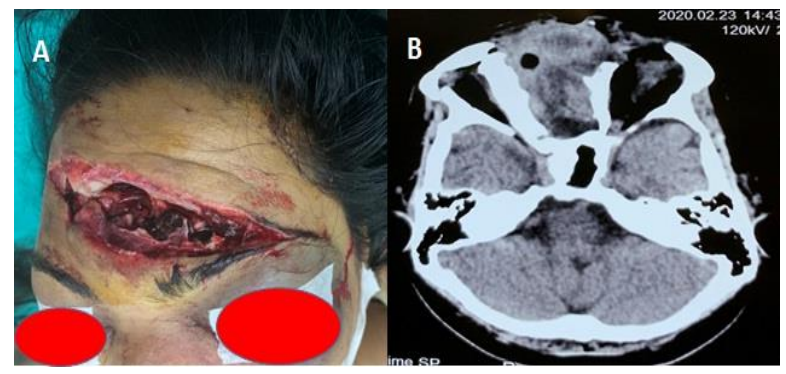

Figure 3. Compound fracture of frontal bone and sinuses B. extradural abscess after 2 months of canalization of frontal sinus.

\section{Conclusion:}

The management of frontonasal remains a challenge for otolaryngology surgeons and neurosurgeons demanding both skill and high level of expertise. Young adults and males were the commonest victims of road traffic accidents. Management of more serious intracranial and life threatening injuries takes priority. Closed reduction is recommended for nasal bone fracture.

\section{References:}

1. Parashar A, Sharma RK. Unfavourable outcomes in maxillofacial injuries: How to avoid and manage. Indian J Plast Surg. 2013 May;46(2):221-34. https://doi.org/ 10.4103/0970-0358.118597.

2. Miloro M, Ghali GE, Larsen PE, Waite PD. Peterson's Principles of Oral and Maxillofacial Surgery. vol. 1. Hamilton: BC Decker Inc; 2004.

3. Ahmad Z, Nouraei R, Holmes S. Towards a classification system for complex craniofacial fractures. $\mathrm{Br} \quad \mathrm{J}$ Oral Maxillofac Surg. 2012 Sep;50(6):490-4. https://doi.org/10.1016/j.bjoms.2011.09.018.

4. Hussain K, Wijetunge DB, Grubnic S, Jackson IT. A comprehensive analysis of craniofacial trauma. J Trauma. $1994 \quad$ Jan;36(1):34-47. https://doi.org/10.1097/00005373-199401000-00006.

5. Byun IH, Lee WJ, Roh TS, Hong JW. Demographic Factors of Nasal Bone Fractures and Social Reflection. J Craniofac Surg. 2020 Jan/Feb;31(1):169-71. https://doi.org/10.1097/SCS.0000000000006065.
6. Kim KS, Lee HG, Shin JH, Hwang JH, Lee SY. Trend analysis of nasal bone fracture. Arch Craniofac Surg. 2018 Dec;19(4):270-4. https://doi.org/10.7181/acfs.2018.02264.

7. Motamedi MHK. An assessment of maxillofacial fractures: a 5-year study of 237 patients. J Oral Maxillofac Surg. $2003 \quad$ Jan;61(1):61-4. https://doi.org/10.1053/joms.2003.50049.

8. O'Meara C, Witherspoon R, Hapangama N, Hyam DM. Alcohol and interpersonal violence may increase the severity of facial fracture. Br J Oral Maxillofac Surg. 2012;50(1):36-40. https://doi.org/10.1016/j.bjoms.2010.11.003.

9. Ong TK, Dudley M. Craniofacial trauma presenting at an adult accident and emergency department with an emphasis on soft tissue injuries. Injury. 1999 Jun;30(5):357-63. https://doi.org/10.1016/S00201383(99)00101-1.

10. Kelley BP, Downey CR, Stal S. Evaluation and reduction of nasal trauma. Semin Plast Surg. 2010 Nov;24(4):339-47. https://doi.org/10.1055/s-00301269763.

11. Jin KS, Lee H, Sohn JB, Han YS, Jung DU, Sim HY, et al. Fracture patterns and causes in the craniofacial region: an 8-year review of 2076 patients. Maxillofac Plast Reconstr Surg. 2018 Oct 15;40(1):29. https://doi.org/10.1186/s40902-018-0168-y.

12. Guy WM, Brissett AE. Contemporary management of traumatic fractures of the frontal sinus. Otolaryngol Clin North Am. 2013 Oct;46(5):733-48. https://doi.org/10.1016/j.otc.2013.07.005.

13. Jeyaraj P. Frontal Bone Fractures and Frontal Sinus Injuries: Treatment Paradigms. Ann Maxillofac Surg. 2019 Jul-Dec;9(2):261-82. https://doi.org/10.4103/ams.ams_151_19.

14. Elahi MM, Brar MS, Ahmed N, Howley DB, Nishtar $\mathrm{S}$, Mahoney JL. Cervical spine injury in association with craniomaxillofacial fractures. Plast Reconstr Surg. 2008Jan;121(1):201-8. https://doi.org/10.1097/01.prs.0000293763.82790.aa.

15. Aurangzeb A, Ahmed E, Afridi EA, Khan SA, Muhammad G, Ihsan A, et al. Frequency of extradural haematoma in patients with linear skull fracture. J Ayub Med Coll Abbottabad. 2015 Apr-Jun;27(2):314$7 . \quad$ Available from: https://jamc.ayubmed.edu.pk/index.php/jamc/article/vi ew/24.

16. Park KP, Lim SU, Kim JH, Chun WB, Shin DW, Kim JY, et al. Fracture patterns in the maxillofacial region: a four-year retrospective study. J Korean Assoc Oral Maxillofac Surg. 2015 Dec;41(6):306-16. https://doi.org/10.5125/jkaoms.2015.41.6.306. 